\title{
Unimed Recife's experience in treating 1,039 patients with Covid-19
}

\author{
Marcelo Moraes Valença, ${ }^{1,2}$ (D) Martha Maria Romeiro Fiqueiroa F. Fonseca ${ }^{2}$ (i) Cátia Arcuri Branco (iD) \\ Alex Maurício Garcia Santos ${ }^{2}$ (i) Antonio Oliveira ${ }^{2}$ (i) Danilo Ferreira Nunes ${ }^{2}$ (D) Ana Carolina Chiappetta \\ Correia de Araújo² iD Fernando Cruz $^{2}$ iD
}

${ }^{1}$ Universidade Federal de Pernambuco, Recife, Pernambuco, Brazil; ${ }^{2}$ Unimed Recife, Recife, Pernambuco, Brazil

\section{$>$}

Marcelo Moraes Valença Unimed Recife, Recife, Pernambuco, Brazil $+5581999229394$ mmvalenca@yahoo.com.br

Edited by

Juliana Ramos de Andrade

\section{Keywords:}

Covid-19

Lethality

Diabetes Mellitus

Obesity

Intensive Care Unit

Mechanical Ventilation

\begin{abstract}
Objective

To describe the features related to patients with Covid-19 admitted to Unimed Recife hospitals, Recife, Brazil, evaluating demographic data, lethality, use of a mechanical ventilator, presence of associated diseases, the need to use the ICU, among other aspects related to the prognosis of these patients.
\end{abstract}

Method

Data were collected from the DRG Brazil health management platform, including the period from March 16, 2020, when the first patient with Covid-19 was admitted to the Hospital da Unimed III, until January 31, 2021. All patients admitted to one of the three hospitals of Unimed Recife - Hospital Unimed Recife I, Hospital Unimed Recife III, and Hospital Geral Unimed Recife - were included in the study. In the same period, we evaluated the number of patients with Covid-19 or suspected Covid-19 who were seen in the emergency room at Hospital Unimed Recife III.

\section{Results}

One hundred twenty-six thousand five hundred fifty-three patients were seen in the Emergency Unit of Hospital Unimed Recife III in the period between March 26, 2020, and January 31, 2021 ; of those 126,553 patients seen in the emergency 39,340 (31.09\%) patients were diagnosed with having Covid-19 or suspected of Covid-19. In the 10-month period, 1039 patients with Covid-19 were hospitalized, $61 \%$ with hypertension, $31.1 \%$ with SARS, $30.0 \%$ with diabetes, and $9.9 \%$ were obese. The average hospital stay was 11.2 days. 342/1,039 (32.9\%) patients were admitted to the ICU, and $57.9 \%$ of them had mechanical ventilation. The overall lethality was $13.76 \%$ (143 deaths 1,039 inpatients). An increase in lethality by Covid-19 was associated with increased age. Lethality in the first period of the Covid-19 pandemic was significantly higher when compared to the last 5 months of the pandemic $(17.6 \%$ versus $9.7 \%$ ). Obesity significantly increased lethality in patients with Covid-19 [120 deaths $/ 1,016$ non-obese patients (11.8\%) versus 23 deaths/103 obese patients $(22.3 \%)$, OR $2.15(1.30-3.50), p=0.005)]$.

Conclusion

We conclude that Covid-19 is a disease with a poor prognosis, especially in the elderly and obese patients. In the second 5-month period of the Covid-19 pandemic, we noticed a significant reduction in lethality by Covid-19 in hospitalized patients. Covid-19 is a new disease and the mechanism by which the viruses multiply or how the pathophysiological process occurs in the infected organism are still barely understood.

This article was also published in Portuguese. (https://doi.org/10.535435/AvanMed.5) 


\section{Introduction}

n December 2019, a new human viral disease emerged in Wuhan, China, and was named Covid-19 ('CO' means corona, 'VI' virus and 'D' means 'disease'; 19 of '2019"). A few months later, the first cases of patients with Covid-19 arrived in Recife. 'It was a couple returning from Europe that arrived at the International Airport of Recife/Guararapes on February 29, 2020. The first patient diagnosed as Covid-19 in South America was a 61 -year-old man who arrived in São Paulo on February 26, 2021, from Italy. ${ }^{1}$

Despite preventive care, there has been an exponential growth in the number of cases in the state of Pernambuco and Brazil. ${ }^{2}$ Only in the hospitals of the Unimed Recife complex, during the year 2020, 894 patients were admitted with Covid-19, who were individuals with a more severe clinical condition that justified the hospitalization.

Some associated conditions in patients with Covid-19 determine a worse prognosis, such as obesity ${ }^{3.6}$, use of inhibitors of the renin-angiotensin system7, arterial hypertension ${ }^{8,9}$, diabetes mellitus ${ }^{5,9}$, elder age ${ }^{7}, 10-14$ being male ${ }^{13-16}$, chronic obstructive pulmonary disease ${ }^{7}$ and chronic kidney disease ${ }^{7}$. The following laboratory parameters are also associated with the prognosis of patients with Covid-19: lymphopenia, elevated levels of C-reactive protein, neutrophil count, interleukin-6, D-dimer, lactic dehydrogenase and troponin $1 .{ }^{15,} 17,18$

In this article, the authors intend to describe data related to the treatment of these patients who were admitted to Unimed Recife hospitals in 2020 and early 2021, evaluating demographic data, lethality, use of mechanical ventilator, presence of conditions that modify the disease prognosis (e.g. diabetes, obesity), need for admission to the Intensive Care Unit (ICU), among other aspects related to the prognosis of these patients.

\section{Methods}

Data were collected on the DRG Brazil Health Management Platform, including the period from March 26, 2020, when the first patient with Covid-19 was admitted to the Hospital da Unimed Recife III, until January 31, 2021. All patients who were admitted to one of the three hospitals in the Unimed Recife - Hospital Unimed Recife I, Hospital Unimed Recife III and Hospital Geral Unimed Recife - participated in the study. In the same period, we evaluated the number of patients with Covid-19 or suspected Covid-19 who were seen in the emergency room at Hospital Unimed Recife III.

The present study was based on Resolution number 466/12 of the National Health Council regarding research with human beings from the signature of the Letter of Consent by the Institution's Board of Directors.

\section{Results}

One hundred twenty-six thousand five hundred fifty-three patients were seen in the Emergency Unit of Hospital Unimed Recife III in the period between March 26, 2020, and January 31, 2021; of those 126,553 patients seen in the emergency 39,340 (31.09\%) patients were diagnosed with having Covid-19 or suspected of Covid-19.

In the 10-month period (March 26, 2020 to January 31, 2021) 1,039 patients with Covid-19 were admitted to one of the three hospitals of Unimed Recife. Figure 1 shows the number of patients with Covid-19 hospitalized per month at Unimed Recife during the period from March 2020 to the end of January 2021.

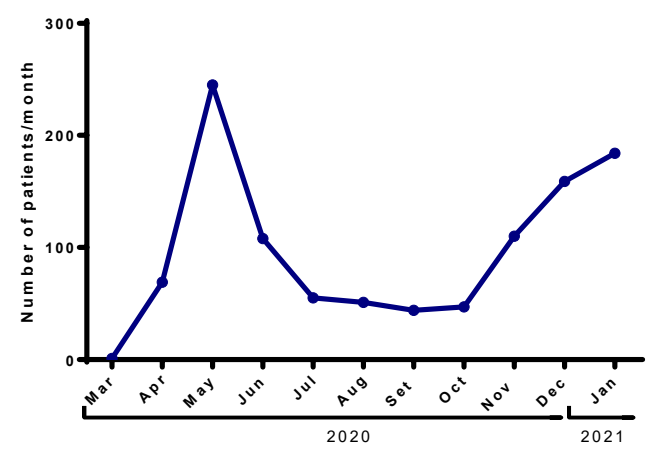

Figure 1. Number of patients with Covid-19 hospitalized per month at Unimed Recife. It should be noted that the frequency of hospitalization follows the epidemiological aspects of the disease in the state of Pernambuco, with a peak in May 2020 and another on the rise starting in November 2020.

All these 1,039 individuals were discharged from hospital or have died. There were 968 (93.2\%) non-surgical patients and $71(6.8 \%)$ surgical patients. Figure 2 shows the distribution of patients according to the age group.

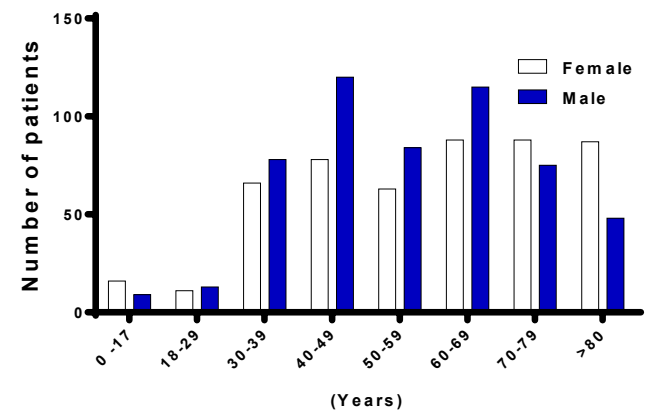

Figure 2. Distribution of 1,039 patients in relation to sex and age group with Covid-19 admitted to one of the three hospitals of Unimed Recife until January 31, 2021.

Table 1 lists the associated conditions in the 1,039 patients with Covid-19. The average hospital stay was 11.2 days (9.4 days for non-surgical patients and 36.6 days for surgical patients). The case mix of non-surgical patients was 2.0293 
and in surgical patients 8.7278 .

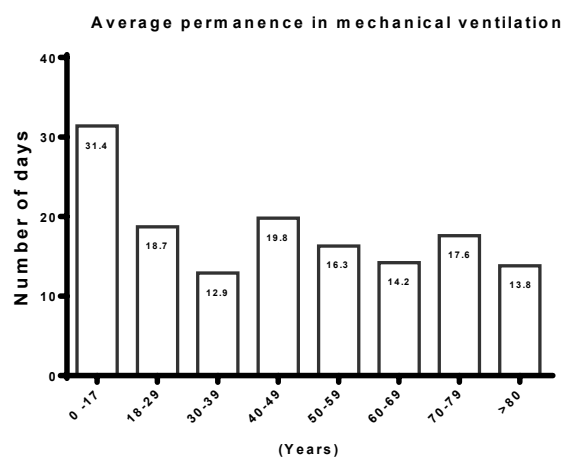

Figure 3. Average permanence (in days) on mechanical ventilation, according to the age group.

Regarding mechanical ventilation, 342/1,039 (32.9\%) patients were admitted to the ICU and $57.9 \%$ of them used mechanical ventilation. Mechanical ventilation was required in 198/1,039 (19.1\%) hospitalized patients. Figure 3 illustrates the average permanence in mechanical ventilation according to the age group. Lethality by age group among patients with Covid-19 who underwent mechanical ventilation is shown in Figure 4.

Table 1. Presence of associated conditions in the 1,039 patients with Covid-19

\begin{tabular}{|l|c|c|}
\hline \multicolumn{1}{|c|}{ Associated diseases } & $\mathrm{n}$ & $\%$ \\
\hline Arterial hypertension & 529 & 60.1 \\
\hline SARS & 281 & 31.9 \\
\hline Diabetes mellitus & 264 & 30.0 \\
\hline Obesity & 103 & 9.9 \\
\hline Acute renal failure & 79 & 10.0 \\
\hline Sepsis & 68 & 7.7 \\
\hline Hypothyroidism & 49 & 5.6 \\
\hline Smoking & 24 & 2.7 \\
\hline Chronic renal failure & 23 & 2.6 \\
\hline
\end{tabular}

SARS, Severe acute respiratory syndrome.

Table 2. Lethality (odds ratio and $95 \%$ confidence interval) observed by age group in the 1,039 patients with Covid-19 admitted to the three hospitals of Unimed Recife until January 31, 2021

\begin{tabular}{|c|c|c|}
\hline $\begin{array}{c}\text { Age } \\
\text { (years) }\end{array}$ & $\begin{array}{l}\text { Odds Ratio ( } 95 \% \text { Confidence } \\
\text { Interval) }\end{array}$ & $\begin{array}{c}p \text {-value } \\
\text { (Fisher exact test) }\end{array}$ \\
\hline $18-29$ & 1 & \\
\hline$<18$ & $0.31(0.01-7.92)$ & 0.490 \\
\hline $30-39$ & $1.00(0.12-8.70)$ & $>0.999$ \\
\hline $40-49$ & $0.12(0.01-1.93)$ & 0.205 \\
\hline $50-59$ & $2.42(0.30-19.32)$ & 0.698 \\
\hline $60-69$ & $3.83(0.50-29.51)$ & 0.216 \\
\hline $70-79$ & 7.73 (1.01-59.07) & 0.019 \\
\hline$\geq 80$ & $13.96(1.83-106.60)$ & $<0.001$ \\
\hline
\end{tabular}

The overall lethality was $13.76 \%$ (143 deaths/1,039 inpatients). There is an increase in Covid-19 lethality with increasing age (Figures 5 and 6 , and Table 2). Table 3 shows the number of deaths per period, comparing the first months of the pandemic (from March to August 2020) versus the last months (from September 2020 to January 2021) among patients with Covid-19 admitted to the Unimed Recife. Lethality in the first period of the Covid-19 pandemic was significantly higher, i.e., $17.6 \%$ versus $9.7 \%$.

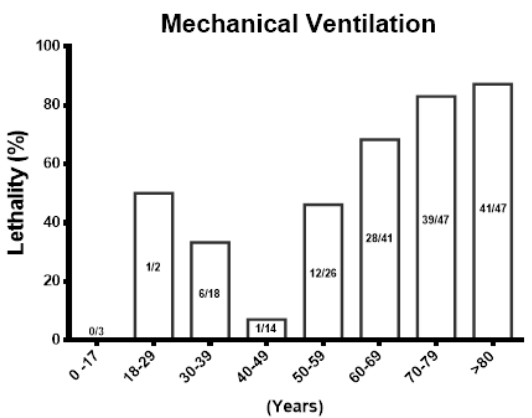

Figure 4. Lethality among patients with Covid-19 who underwent mechanical ventilation by age group.

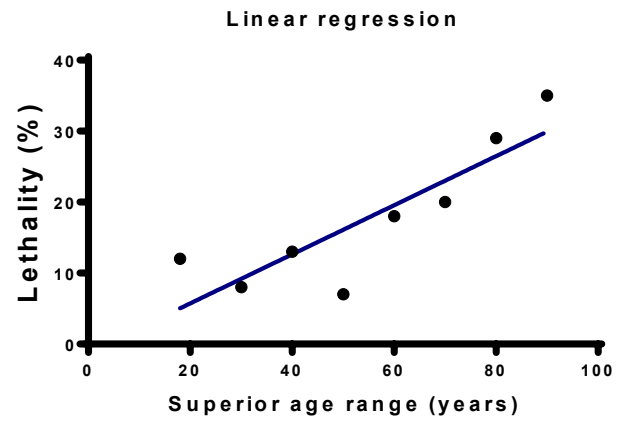

Figure 5. Linear regression between lethality and age in the 1,039 patients with Covid-19. R2 0.07463; slope $0.34 \pm 0.08$ (95\% Cl $0.01-0.55), p=0.006$ (F 17.65).

Obesity significantly increased lethality in patients with Covid-19 [120 deaths/1,016 non-obese patients (11.8\%) versus 23 deaths/103 obese patients (22.3\%), OR 2.15 $(1.30-3.50), p=0.005)]$.

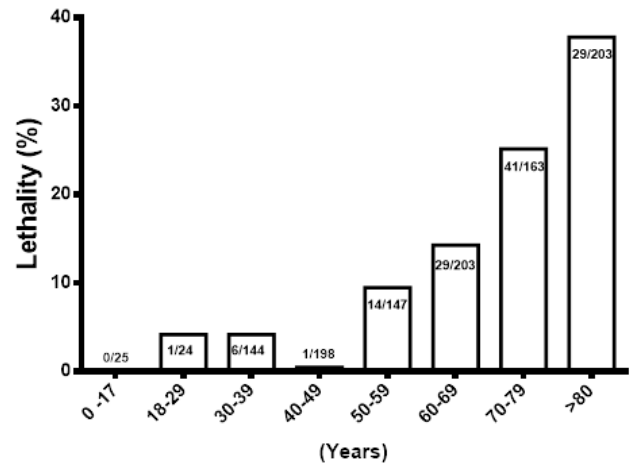

Figure 6. Lethality by Covid-19 in patients admitted to Unimed Recife according to age group. 
Table 3. Number of deaths per period in comparison between the first months of the pandemic (from March to August 2020) versus the last months (from September 2020 to January 2021) among patients with Covid-19 admitted to Unimed Recife

\begin{tabular}{|l|c|c|c|c|}
\hline \multicolumn{1}{|c|}{ Period } & $\begin{array}{c}\text { Number } \\
\text { of patents } \\
\text { admitted }\end{array}$ & $\begin{array}{c}\text { Number of } \\
\text { deaths }\end{array}$ & OR $(95 \%$ Cl) & $p$-value \\
\hline $\begin{array}{l}\text { March/2020 } \\
\text { August/2020 }\end{array}$ & 534 & $94(17.6 \%)$ & $\begin{array}{c}1.99 \\
(1.37-2.88)\end{array}$ & $<0.001$ \\
$\begin{array}{l}\text { September/2020 } \\
\text { - January/2021 }\end{array}$ & 505 & $49(9.7 \%)$ & & \\
\hline
\end{tabular}

\section{Discussion}

In this study, the authors have evaluated Unimed Recife's experience in its three hospitals to treat hospitalized patients with Covid-19. Since the patient was admitted to a hospital, it is understood that there is a clear tendency in the study to find patients with the worst spectrum of disease severity. Most patients with Covid-19 were seen in the emergency room for the correct diagnosis and due therapeutic guidance without the need for hospitalization. It is also clear that the frequency of hospitalization throughout the year 2020 has a profile like the epidemiological aspects of the disease in the state of Pernambuco, with a peak in May 2020 and another one on the rise starting in November 2020.

When assessing lethality in relation to age, as expected, it was significantly higher in the older age groups and in patients who required mechanical ventilation. There are several factors associated with lethality in Covid-19. ${ }^{19-25}$ Many of the patients who were hospitalized had comorbidities linked to a worse prognosis in Covid-19, such as $\mathrm{SAH}(60 \%)$, diabetes mellitus (30\%) and obesity (10\%). ${ }^{21}$

One of the first published studies on patients with Covid-19 evaluated 191 patients who were admitted to two hospitals in Wuhan, China, ${ }^{26}$ until January 31, 2020. Of the 191 patients, $53(28.3 \%)$ died. The authors report that 91 (48\%) of the patients had comorbidities, such as: systemic arterial hypertension (30\%), diabetes (19\%) and coronary disease (8\%). The study showed after analysis by multivariable regression an association of more advanced age, a high score on the SOFA (Sequential Organ Failure Assessment) and high D-dimer level. ${ }^{26}$

In Brazil, the experience of the Sírio-Libanês Hospital ${ }^{27}$ has been published and deserves comment. The study sample was 212 adult patients with Covid-19, admitted to the ICU between March 8, 2020 and June 30, 2020. The authors compared this group with another group with 185 patients without Covid-19 who were admitted to the same ICU in the previous year of 2019. When compared to historical controls, patients with Covid-19 required more ventilatory support, longer ventilation time mechanics and were hospitalized for a greater number of days in the ICU and in the hospital. Interestingly, there was no statistical difference in lethality. A higher proportion of men (55.7\% versus $75.9 \%$ ) and morbid obesity $(7.5 \%$ versus $2.2 \%)$ was also observed. In this series of patients with Covid-19 admitted to the ICU, lethality was $9.0 \%$ (16.2\% in patients who received mechanical ventilation) with 28 days, and $10.8 \%$ (19.0\% in patients who received mechanical ventilation) with 60 days. During hospitalization, it was observed that $50.9 \%$ used vasopressors, $49.5 \%$ underwent invasive mechanical ventilation, $49.1 \%$ with noninvasive mechanical ventilation with positive pressure, $46.7 \%$ received high flow nasal ventilation, $10.8 \%$ of patients underwent tracheostomy, $13.2 \%$ received renal dialysis, and the duration of mechanical ventilation was 9 days (6-16, median IQR). The median length of stay in the ICU was of seven days, when the patient required mechanical ventilation, the duration was 9 days (median).

It is known that the comparison of statistical data between different institutions is impossible because the criteria for admission to the hospital or the ICU are different, the patient population may also have particularities related to their own socio-cultural and economic level.

In a cross-sectional study based on data from 204 patients admitted to the Hayatabad Medical Complex ICU in Pakistan, the overall lethality was $77 \% .{ }^{28}$ Noninvasive ventilation was used by $61.8 \%$ of patients. ${ }^{28}$ Lethality was higher for invasive mechanical ventilation ( $93.6 \%$ versus $66.7 \%, p<0.001$ ) and in patients over 60 years of age $(87.3 \%$ versus $72.3 \%, p=$ $0.019)$. Lethality without comorbidities was $75.2 \% .{ }^{28}$ This study shows an alarming lethality in patients with Covid-19 admitted to the ICU.

Another study carried out in Italy ${ }^{7}$ with data from 1,590 (64\% men, $66 \pm 0.4$ years) patients hospitalized with Covid-19 in 26 hospitals, hypertension was recorded in $54.9 \%$ of them. Lethality was $11.8 \%$, with this group of patients who died age of $89.6 \pm 0.9$ years old. ${ }^{7}$ When comparing the group of non-survivors with the group of survivors, there was a higher frequency of advanced age, hypertension, diabetes mellitus, chronic obstructive pulmonary disease, chronic kidney disease, coronary artery disease and heart failure. ${ }^{7}$ Charlson's comorbidity rate was significantly higher in non-survivors (4.3 \pm 0.15 versus $2.6 \pm 0.05) .{ }^{7}$ Regarding drugs, angiotensin converting enzyme inhibitors, diuretics and beta-blockers were used more frequently in patients in the non-surviving group. However, after correction by multivariate analysis, only age, diabetes mellitus, chronic obstructive pulmonary disease, and chronic kidney disease were associated with lethality.

A Chinese study of 996 patients (282 with arterial hypertension) aimed to assess the impact of hypertension on Covid-19 and to verify whether the previous use of inhibitors of the renin-angiotensin-aldosterone system would alter the prognosis. ${ }^{29}$ It was interesting to notice the fact that patients with Covid-19 with hypertension had more severe secondary infections, cardiac and renal abnormalities and depletion of CD8 $(+)$ cells at admission. Hypertensive patients with a history of treatment 
with a renin-angiotensin-aldosterone system inhibitor had lower levels of C-reactive protein and higher levels of CD4(+) cells. Lethality was lower in patients in the inhibitor group $(9.8 \%$ versus $26.1 \%$ ). The authors concluded that hypertension may be an independent risk factor for all causes of mortality in patients with Covid-19 and those who previously used inhibitors of the renin-angiotensin-aldosterone system had a better prognosis. Regarding age as a risk factor, a study carried out in Mexico with 101,728 patients with Covid-19, showed that in the group of 20,804 patients aged $\geq 60$ years $(20.5 \%)$ the lethality was higher $(6.95 \%$ versus $29.49 \%){ }^{13}$

Concerned about knowing the lethality rate (regardless of whether the patient was admitted to a hospital or not) by Covid-19 in Rondônia, Brazil, the researchers found that 1,020 (2.1\% lethality) of 49,804 patients with Covid-19 died. ${ }^{14}$ There was a higher lethality rate among patients $\geq 80$ years of age $(24.89 \%)$ when compared to patients aged $20-39$ years $(0.34 \%) .^{14}$

Diagnosis Related Groups (DRG) it is part of a patient classification system developed at Yale University, in the United States, in a way that serves as an instrument for the management of a hospital, allowing measurement and evaluation of performance..$^{30}$ It is a versatile and very important tool for researches, because it efficiently stores data from patients admitted to a hospital, allowing comparisons. The data used in the present study were obtained from a DRG platform.

Case mix is understood as the relative proportion of different types of patients receiving treatment in the hospital. ${ }^{30}$ Carnielo ${ }^{31}$ argues and defines the term case mix as "a measure of hospital complexity and criticality based on age, a disease that determined hospitalization, pre-existing diseases and procedures performed, used worldwide since the 1980s and measured by the DRG methodology." In our study, the case mix of patients with surgical Covid-19 was higher in relation to non-surgical patients.

\section{Conclusion}

We conclude that Covid-19 is a disease with a poor prognosis, especially in the elderly patients, with diabetes mellitus, high blood pressure and obesity. In the second phase of the Covid-19 pandemic, we noticed a significant drop in lethality in hospitalized patients with Covid-19. Covid-19 is a new disease, still little known, and in the first months it was not very well understood about the mechanisms by which the virus multiplied or how the pathophysiological process occurred. Much has been learned about the disease in recent months, probably the decrease in lethality is the result of clinical studies on the best way to treat Covid-19. In this period from March 2021 to February 2021, six clinical protocols were developed or updated at Unimed Recife related to the treatment of the patient with Covid-19, showing the changes in conduct towards a critically ill patient with this disease with a high rate of lethality.

Funding: The authors received no specific funding for this work. Conflict of Interest: On behalf of all authors, the corresponding author states that there is no conflict of interest.

Author contributions MMV, FC Study concept and design; MMV, FC Collected the Data; MMV Analysis and interpretation of data; $M M V$ Drafting of the manuscript; FC, MMV Revising it for intellectual content; MMRFF, CAB, AMGS, DFN, AO contributed data or analysis tools; MMV, MMRFFF, CAB, AMGS, DFN, ACCCA, FC, AO Final approval of the manuscript.

Marcelo Moraes Valença

https://orcid.org/0000-0003-0678-3782

Martha Maria Romeiro Figueiroa F. Fonseca

https://orcid.org/0000-0003-4929-6343

Cátia Arcuri Branco

https://orcid.org/0000-0002-7082-9223

Alex Maurício Garcia Santos

https://orcid.org/ 0000-0002-7472-041X

Antonio Oliveira

https://orcid.org/0000-0003-4368-5305

Danilo Ferreira Nunes

https://orcid.org/

Ana Carolina Chiappetta Correia de Araújo

https://orcid.org/

Fernando Cruz

https://orcid.org/0000-0002-6152-6888

\section{References}

1. Tang Y, Serdan TDA, Masi LN, Tang S, Gorjao R, Hirabara SM. Epidemiology of COVID-19 in Brazil: using a mathematical model to estimate the outbreak peak and temporal evolution. Emerg Microbes Infect. 2020;9:14531456.

2. Souza WV, Martelli CMT, Silva A, et al. The first hundred days of COVID-19 in Pernambuco State, Brazil: epidemiology in historical context. Cad Saude Publica. 2020;36:e00228220.

3. Goossens GH, Dicker D, Farpour-Lambert NJ, et al. Obesity and COVID-19: A Perspective from the European Association for the Study of Obesity on Immunological Perturbations, Therapeutic Challenges, and Opportunities in Obesity. Obes Facts. 2020;13:439-452.

4. Aghili SMM, Ebrahimpur M, Arimand B, et al. Obesity in COVID-19 era, implications for mechanisms, comorbidities, and prognosis: a review and meta-analysis. Int J Obes (Lond). 2021.

5. Zhou Y, Chi J, Lv W, Wang Y. Obesity and diabetes as high-risk factors for severe coronavirus disease 2019 (Covid-19). Diabetes Metab Res Rev. 2021;37:e3377.

6. Sanchis-Gomar F, Lavie CJ, Mehra MR, Henry BM, Lippi G. Obesity and Outcomes in COVID-19: When an Epidemic and Pandemic Collide. Mayo Clin Proc. 2020;95:1445-1453.

7. laccarino G, Grassi G, Borghi C, Ferri C, Salvetti M, Volpe M. Age and Multimorbidity Predict Death Among COVID-19 Patients: Results of the SARS-RAS Study of the Italian Society of Hypertension. Hypertension. 2020;76:366-372.

8. Kamyshnyi A, Krynytska I, Matskevych V, Marushchak $M$, Lushchak O. Arterial Hypertension as a Risk Comorbidity Associated with COVID-19 Pathology. Int J Hypertens. 2020;2020:8019360. 
9. Shah H, Khan MSH, Dhurandhar NV, Hegde V. The triumvirate: why hypertension, obesity, and diabetes are risk factors for adverse effects in patients with COVID-19. Acta Diabetol. 2021.

10. $\mathrm{Xu}$ PP, Tian RH, Luo $\mathrm{S}$, et al. Risk factors for adverse clinical outcomes with COVID-19 in China: a multicenter, retrospective, observational study. Theranostics. 2020; 10:6372-6383.

11. Alamdari NM, Afaghi S, Rahimi FS, et al. Mortality Risk Factors among Hospitalized COVID-19 Patients in a Major Referral Center in Iran. Tohoku J Exp Med. 2020;252:73-84.

12. Dai Z, Zeng D, Cui D, et al. Prediction of COVID-19 Patients at High Risk of Progression to Severe Disease. Front Public Health. 2020;8:574915.

13. Bello-Chavolla OY, Gonzalez-Diaz A, Antonio-Villa NE, et al. Unequal Impact of Structural Health Determinants and Comorbidity on COVID-19 Severity and Lethality in Older Mexican Adults: Considerations Beyond Chronological Aging. J Gerontol ABiol Sci Med Sci. 2021;76:e52-e59.

14. Escobar AL, Rodriguez TDM, Monteiro JC. Lethality and characteristics of deaths due to COVID-19 in Rondonia: an observational study. Epidemiol Serv Saude. 2020;30:e2020763.

15. Ebell MH, Cai $X$, Lennon $R$, et al. Development and Validation of the COVID-NoLab and COVID-SimpleLab Risk Scores for Prognosis in 6 US Health Systems. J Am Board Fam Med. 2021;34:S127-S135.

16. Brandi ML, Giustina A. Sexual Dimorphism of Coronavirus 19 Morbidity and Lethality. Trends Endocrinol Metab. 2020;31:918-927.

17. Fu L, Wang B, Yuan T, et al. Clinical characteristics of coronavirus disease 2019 (COVID-19) in China: A systematic review and meta-analysis. J Infect. 2020;80:656-665.

18. Moutchia J, Pokharel P, Kerri A, et al. Clinical laboratory parameters associated with severe or critical novel coronavirus disease 2019 (COVID-19): A systematic review and meta-analysis. PLoS One. 2020; 15:e0239802.

19. Alamer AA, Almulhim AS, Alrashed AA, Abraham I. Mortality, Severity, and Hospital Admission among COVID-19 Patients with ACEI/ARB Use: A Meta-Analysis Stratifying Countries Based on Response to the First Wave of the Pandemic. Healthcare (Basel). 2021;9.

20. Solano-Lopez J, Zamorano JL, Pardo Sanz A, et al. [Risk factors for in-hospital mortality in patients with acute myocardial infarction during the COVID-19 outbreak]. Rev Esp Cardiol. 2020;73:985-993.

21. Rastad H, Karim H, Ejtahed HS, et al. Risk and predictors of in-hospital mortality from COVID-19 in patients with diabetes and cardiovascular disease. Diabetol Metab Syndr. 2020; 12:57.

22. Rieg $S$, von Cube $M$, Kalbhenn J, et al. COVID-19 in-hospital mortality and mode of death in a dynamic and non-restricted tertiary care model in Germany. PLOS One. 2020; 15:e0242127.

23. Nie L, Dai K, Wu J, et al. Clinical characteristics and risk factors for in-hospital mortality of lung cancer patients with COVID-19: A multicenter, retrospective, cohort study. Thorac Cancer. 2021;12:57-65.

24. Janke AT, Mei H, Rothenberg C, Becher RD, Lin Z, Venkatesh AK. Analysis of Hospital Resource Availability and COVID-19 Mortality Across the United States. J Hosp Med. 2021.

25. Zhang G, An Y, Zhang L, Xie L, Guo X. Risk factors for in-hospital mortality in patients with cancer and COVID-19. Lancet Oncol. 2020;21:e407.

26. Zhou $F, Y u T, D u R$, et al. Clinical course and risk factors for mortality of adult inpatients with COVID-19 in Wuhan, China: a retrospective cohort study. Lancet. 2020;395:1054-1062.

27. Socolovithc RL, Fumis RRL, Tomazini BM, et al. Epidemiology, outcomes, and the use of intensive care unit resources of critically ill patients diagnosed with COVID-19 in Sao Paulo, Brazil: A cohort study. PLoS One. 2020; 15:e0243269.

28. Rahim F, Amin S, Noor M, et al. Mortality of Patients With Severe COVID-19 in the Intensive Care Unit: An Observational Study From a Major COVID-19 Receiving Hospital. Cureus. 2020; 12:e10906.

29. Pan W, Zhang J, Wang M, et al. Clinical Features of COVID-19 in Patients With Essential Hypertension and the Impacts of Renin-angiotensin-aldosterone System Inhibitors on the Prognosis of COVID-19 Patients. Hypertension. 2020;76:732-741.

30. Noronha MF, Portela MC, Lebrao ML. [Potential uses of AP-DRG to describe the health care profile in hospital units]. Cad Saude Publica. 2004;20 Suppl 2:S242-255.

31. Carnielo M. Especialista pontua os desafios da saúde pós-pandemia. In. Portal Hospitais Brasil; 2021. 